\title{
THE USE OF MICRO-OSTEOPERFORATION CONCEPT FOR ACCELERATING DIFFERENTIAL TOOTH MOVEMENT
}

\author{
Zoya Ahsan, Mehwish Khan, Abdullah Jan, Tooba Ishtiaq Shah, Saad Naeem \\ Armed Forces Institute of Medical Sciences/National University of Medical Sciences (NUMS) Rawalpindi Pakistan
}

\begin{abstract}
Objective: To compare the rate of accelerated tooth movement in canine retraction with micro-osteoperforation on one side and control on the other.

Study Design: Quasi experimental study.

Place and Duration of Study: Orthodontics department, Armed Forces Institute of Dentistry, Rawalpindi Pakistan, from Jul 2018 to Jan 2019.

Methodology: A total of 30 patients were inducted. After alignment and extraction of maxillary first premolars, canine retraction was started with closed NiTi coil spring on both sides of the maxillary arch. Micro-osteoperforation was done on the right side and other side was a control side. The distance between the lateral incisor and the canine was measured on both sides before micro-osteoperforation. The same measurements were recorded after three weeks of retraction. The difference between pre and post retraction measurements was recorded. The difference in the rate of canine retraction between both modalities was compared using independent sample t-test.

Results: The study included 17 males (56\%) and 13 females (43\%). The mean rate of tooth movement at experimental side of maxilla was $1.6 \pm 0.52 \mathrm{~mm}$ and on control side was $0.66 \pm 0.31 \mathrm{~mm}(p<0.05)$.

Conclusion: Micro-osteoperforation was an effective, comfortable, and safe procedure to accelerate tooth movement (1.6 times in accordance with this study). It significantly shorten the duration of orthodontic treatment.
\end{abstract}

Keywords: Differential tooth movement, Orthodontists, Regional acceleratory phenomenon.

\footnotetext{
This is an Open Access article distributed under the terms of the Creative Commons Attribution License (https://creativecommons.org/licenses/by-nc/4.0/), which permits unrestricted use, distribution, and reproduction in any medium, provided the original work is properly cited.
}

\section{INTRODUCTION}

A number of patients undergoing orthodontic treatment are worried about the duration of treatment because of physical and social uneasiness related to prolonged use of fixed appliances. Duration of treatment is the main element that determine the compliance of patients with orthodontic treatment plan. However the major challenge is reducing treatment time, avoiding undesirable side effects and achieving desirable end results. In the recent years, introduction of new procedures and treatment modalities has escalated the orthodontic tooth movement process $^{1}$. Thus, reducing the usual duration to 18.1 from 24.5 months and to 19.4 from 27.9 months for non-extraction and extraction orthodontic cases respectively2.

As, long span of orthodontic treatments can have detrimental effects on the dentition and its housing like greater risk of gingival inflammation, dental caries, root resorption (external) and decalicification ${ }^{2}$. It leads the orthodontists to embark onto the regional acceleratory phenomenon (RAP) procedures ${ }^{3}$. By their virtue of shortening the orthodontic treatment time regional acceleratory phenomenon (RAP) procedures benefit

Correspondence: Dr Zoya Ahsan, Orthodontics Department, Armed Forces Institute of Dentistry, Rawalpindi Pakistan

Received: 13 Oct 2019; revised received: 17 Dec 2019; accepted: 10 Jan 2020 both the patient and clinician. Decrease time in fixed appliances moderates the possibility of external root absorption, demineralization and caries ${ }^{4}$. There are several non-surgical and surgical techniques which anticipate fast orthodontic tooth movement, by affecting the osteoclastic activity and bone turnover rate. The RAP procedures include non-surgical interventions like self-ligating brackets design, drugs (vitamin D, prostaglandin, interleukins, parathyroid hormone, misoprostol) and Physical/mechanical stimulation interventions like vibrations (cyclic forces), direct electric currents, pulsed electromagnetic fields, low level laser therapy, photo-biomodulation and Surgical modalities such as corticotomy, micro-osteoperforations (MOP), wilkodontics, piezocision, dentoalveloar distraction, periodontal distraction, monocortical tooth dislocation $\&$ ligament distraction, surgery first approach ${ }^{2,5}$.

In this article, the role of micro-osteoperforation is emphasized. Alikhani $e^{2}$ al ${ }^{4}$ introduced this procedure. It is one of the least invasive procedures that cause minimal discomfort to patient with minor complications. Type of movement, bone anatomy and anchorage needs should be taken into consideration by the orthodontists to achieve desired results. Detailed medical and dental history should be taken before the procedure including allergy to any element of local anesthetic, excessive alcohol and tobacco use and conditions 
like uncontrolled Diabetes Mellitus. "Propel" device is used by which; three perforations in a triangular or straight fashion through the gingiva into the cortical bone are made in the interproximal region. This in turn generates regional acceleratory phenomenon ${ }^{6}$.

Orthodontic Tooth Movement (OTM) by applying mechanical forces is a biological process characterized by the remodeling of the periodontal tissue including periodontal ligament (PDL) and alveolar bone. Alveolar bone remodeling comprises selective resorption in some area and apposition in other in reaction to the orthodontic force which will promote extensive cellular, mechanical and chemical response ${ }^{2}$. The PDL stress will lead to release of different inflammatory mediators which in turn modify the activity of osteoblasts and osteoclasts for bone resorption ${ }^{7}$. The biological response also includes the response of the growing areas which are far from the dentition.

Frost ${ }^{8}$ proposed the Regional accelerated phenomenon, in which an insult to the bone escalates the process of healing: which includes modeling, remodeling, cell turnover, metabolism and inflammation. Micro-osteoperforation (MOP) procedure enhances the cytokine release, which in turn employs osteoclasts, enhancing the bone remodeling process ${ }^{9}$. Micro-osteoperforation is not only restricted to accelerating tooth movement but also can be used in scenarios with dense cortical bones where prior orthodontic treatment cannot be performed or did not generated desire results. It can also be used to facilitate root movement in cases like intrusions, extrusions and closure of large space, movement into deficient alveolar bone in situations where old extraction space is needed to be closed, asymmetric expansion and differential anchorage. Microosteoperforation also decrease the possibility of root resorption by decreasing bone density and by limiting the period of exposure to osteoclast, it also improve dental expansion in adults with less possibility of recession. Micro-osteoperforation can be used as a complementary procedure with any orthodontic device, both fixed appliances like braces and removable appliances such as expanders and distalizers.

Decreasing treatment time without compromising treatment outcome has led the orthodontists to embark upon different solutions i.e. chemical agents, physical agents and surgical approaches. The aim of the study was to introduce simple effective cost beneficial biocompatible method to enhance rate of tooth movement. Micro-osteoperforation is a newer concept that acts by augmenting the patient's ordinary biological reaction to the orthodontic forces ${ }^{4}$. The purpose of doing this study was to establish the role of micro-osteoperforation in accelerating regional tooth movement in orthodontic treatment.

\section{METHODOLOGY}

This study was conducted at Armed forces institute of dentistry, department of orthodontics. This was a quasi-experimental study. Study was approved by the research and ethical committee (IERB No. 905/TrgABP1K2). The split mouth study was done in which micro-osteoperforation (MOP) was done on one side (right) and the other side was a control side. The patients selected were those, who required maxillary first premolars extraction. Duration of study was 6 months from July 2018 to January 2019. Thirty patients who attended the orthodontic clinic during the duration of study were selected randomly.

This study includes both male and female patients between the ages 18-30 years without gingivitis, periodontitis, no radiographic evidence of bone loss and systemic illness or were not using any type of medication like anti-inflammatory drugs, corticosteroids, calcium channel blockers, immunosuppressant, long term antibiotic therapy, skeletal Class I \& II as conformed by cephalometric radiographs and non-smokers. Exclusion criteria was patients having skeletal class III malocclusion, probing depth greater than $4 \mathrm{~mm}$, dental cross bites, temporomandibular joint problems (TMJ ankylosis), facial asymmetry and deviation in closing due to occlusal interferences, restorations or untreated carious lesions.

Informed consent was taken from patients undergoing orthodontic treatment and fulfilling selection criteria. They were randomly allocated to the study groups. After the completion of alignment, maxillary first premolars were extracted (only upper first premolars). To augment anchorage, retraction was not initiated until $17 \times 25$ SS wire was inserted. A day prior to surgery patient was asked to rinse in the morning and evening (twice) with $0.12 \%$ chlorhexidine mouth wash. Before the commencement of micro-osteoperforation the patient was instructed to rinse with chlorhexidine containing mouthwash for a minute. Patient was seated on a Belmont-Clesta II dental chair and was evaluated by the same doctor on every appointment. The site was cleaned with sterile gauze. Patient was locally anesthetized with $2 \%$ lignocaine with adrenaline $0.001 \%$ (composed of lignocaine $44 \mathrm{mg}$ and adrenaline $22 \mathrm{mcg}$ ). A TAD screw diameter of $1.6 \mathrm{~mm}$ was used to make three perforations distal to canine to a depth of 
$3 \mathrm{~mm}$ in to the bone on the right side, as shown in figure. No flap was raised; no pain or antibiotic medi-

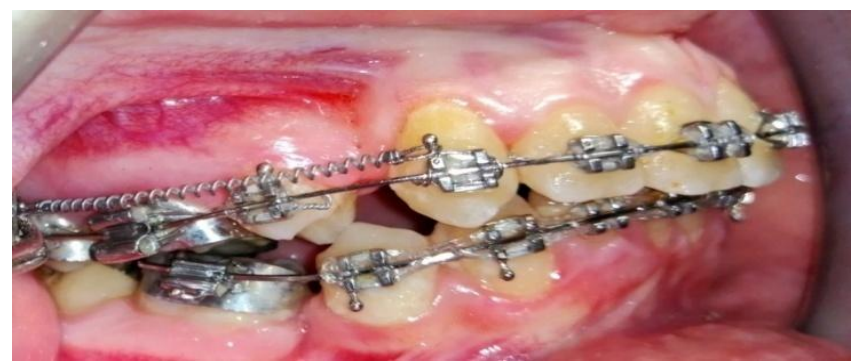

Figure: MOPs done in a linear pattern distal to canine.

cation was given. On the other side no such procedure was performed and conventional mechanics were used. After this procedure was carried out, canine retraction was initiated with the help of NiTi retraction coil spring $(6 \mathrm{~mm})$ on both sides. The hooks of the retraction coil spring were attached anteriorly with canine bracket hook and posteriorly on the molar tube hook. Patient's intraoral distance between second premolar and canine was measured at incisal, middle and cervical region with the help of inner arms of Vernier calipers and mean were taken. Patient was recalled and distance was remeasured on both sides of the patient mouth after three weeks interval at the level of incisal, middle and cervical third of the crown. After 3 weeks the patients were continued with their treatment at AFID, orthodontics department. The amount of tooth movement on both the sides i.e. control side and the experimental side, was calculated. Means and Standard deviation of tooth movement were calculated, ttest was applied and $p$-value was calculated. The $p$ value of $\leq 0.05$ was considered significant.

\section{RESULTS}

Thirty patients were selected who attended the orthodontic clinic during the duration of study. Study was completed without losing any patient to follow up. The study included 17 males (56\%) and 13 females $(43 \%)$. Mean age of participants is $21.7 \pm 2.98$ years.

The mean rate of tooth movement at experimental side of maxilla was $1.66 \pm 0.52 \mathrm{~mm}$ and on control side was $0.66 \pm 0.31 \mathrm{~mm}$. In general rate of canine retraction was much higher on experimental side as compared to control side.

The difference of tooth movement progress was quite elevated as compared to other side where no intervention like micro-osteoperforation was performed. The difference of rate of tooth movement between two groups were statistically significant i.e $p$-value $=0.038$ (table).
Table: Tooth movement in maxilla in both experimental and control groups $(n=30)$.

\begin{tabular}{l|c|c} 
Groups & $\begin{array}{c}\text { Mean } \pm \text { SD of tooth } \\
\text { movement rate }(\mathbf{m m} / \text { day) }\end{array}$ & \multirow{2}{*}{$\boldsymbol{p}$-value } \\
\hline Control & $0.66 \pm 0.31$ & \multirow{2}{*}{0.038} \\
\hline Experimental & $1.61 \pm 0.52$ & \\
\hline
\end{tabular}

\section{DISCUSSION}

Movement of canine retraction is of primordial importance in orthodontic treatment. Recent advances in orthodontics have been made which aim at the acceleration of orthodontic tooth movement. There are several methods employed in orthodontics for canine retraction like bennet retraction, Niti coil spring, different retraction loops which engage the canine bracket anteriorly and auxiliary tube on molar band posteriorly. One of the recent advances is micro-osteoperforation (MOP) which enhances orthodontic tooth movement by rapid acceleratory phenomenon ${ }^{10}$.

This study was done to evaluate rate of tooth movement after micro-osteoperforation. Our study demonstrated that canine retraction after micro-osteoperforation on buccal cortex without any surgical intervention was increased by 1.6 times. Our findings indicated there was increase in tooth movement as compared to control side. But there are several factors that can effect tooth movement like occlusal forces ${ }^{11}$.

Another important factor was the type of tooth movement tipping and bodily movement ${ }^{12,13}$ but in our study force was applied near the center of resistance of canine by sliding mechanism on heavy SS wire $(17 \times 25$ SS). Age of patient is another factor that effect the rate of tooth movement because density of the bone and regional acceleratory phenomenon varies with age and to minimize this factor age group from 18-30 years was selected $^{14,15}$.

Feizbakhsh et al ${ }^{6}$ showed that 2.3 times increase in canine retraction as compared to control group. This shows similar results to our findings. Ren et all6 reported that, 28 days after procedure the tooth movement was increased by 2.13 times in experimental rats.

A study was conducted in thirty adults with Class II Division 1 malocclusion. The rate of tooth movement was increased by 2.4 fold with micro-osteoperforation; there was also a significant rise in the levels of inflammatory markers ${ }^{17}$.

Cramer et al ${ }^{18}$ conducted a study on effects of micro-osteoperforation on tooth movement and bone in beagle maxilla in May 20197. beagle dogs were incorporated in the split mouth study. MOPs were done 3 
mm away from the dentition. It was concluded that MOPs did not increased the rateof tooth movements and have partial and temporary effect on bone.

Aboalnaga et al 19 concluded in his study that micro osteoperforation doesn't accelerate the tooth movement in canine retraction rather effects the movement of the root. The study sample included 18 patients and MOPs were conducted with mini screws of dimensions $1.8 \mathrm{~mm}$ diameter and length $8 \mathrm{~mm}$ between the canine and premolar. For four months canine retraction was carried out.

Research conducted at Rehman Dental College, Pakistan. In which they studied the effect of miniscrews perforation with maxillary canine retraction rate. This study was aimed at the evaluation of rate of canine retraction with flapless cortical perforations with a mini screw. Thirty adult patients of class II div 1 malocclusion with premolars extracted were taken and canine retraction was initiated. Three bilateral cortical flapless cortical perforations were made with the selftapping mini screw of $1.5 \mathrm{~mm}$ diameter and patients were reviewed on 28th day after the initiation of canine retraction. It was concluded that micro-osteoperforation accelerate the tooth movement 2-3 folds in the first month ${ }^{20,21}$.

This was the first study of its kind conducted at AFID on the outcome of micro-osteoperforation on rate of tooth movement. This study concludes that MOPs significantly enhance the rate of tooth movement by 1.6 folds. Moreover, it is a safe procedure and effectively accelerates the tooth movement.

\section{LIMITATION OF STUDY}

Readings of canine retraction taken clinically might be less accurate as compared to the ones taken on dental models or 3-D superimpositions. The study was conducted on a limited time frame; it didn't encompass the entire orthodontic treatment.

Effect of MOPs on root resorption needed to be studied more. Although no patient in this study showed any significant signs of root resorption on final panoramic radiographs. However, panoramic radiographs aren't precise enough to measure the amount of root resorption.

\section{CONCLUSION}

MOPs increased the rate of canine retraction by 1.6 folds as compared to the control side. MOPs are an effective, safe and comfortable method to increase the rate of tooth movement. Patients undergoing MOPs experienced minimal discomfort at the site.

\section{CONFLICT OF INTEREST}

This study has no conflict of interest to be declared by any author.

\section{REFERENCES}

1. Nicozisis J. Accelerated orthodontics through micro-osteoperforation. Orthodontic Practice US 2013; 4(3): 56-57.

2. Safir NK, Athar S, Prashantha GS. Acceleratory orthodontics-the race against time. J Dent Orofac Res 2018; 14(2): 80-87.

3. Tsai CY, Yang TK, Hsieh HY, Yang LY. Comparison of the effects of micro-osteoperforation and corticision on the rate of orthodontic tooth movement in rats. Angle Orthod 2015; 86(4): 558-64.

4. Alikhani M, Alansari S, Sangsuwon C, Alikhani M, Chou MY, Alyami B, et al. Micro-osteoperforations: Minimally invasive accelerated tooth movement. In Seminars in Orthodontics 2015; 21(1): 162-69.

5. Shenava S, Nayak KU, Bhaskar V, Nayak A. Accelerated orthodontics-a review. Int J Sci Study 2014; 1(5): 35-39.

6. Feizbakhsh M, Zandian D, Heidarpour M, Farhad SZ. The use of micro-osteoperforation concept for accelerating differential tooth movement. J World Fed Orthod 2018; 7(2): 56-60.

7. Isola G, Matarese G, Cordasco G, Perillo L. Mechanobiology of the tooth movement during the orthodontic treatment: a literature review. Minerva stomatologica 2016; 65(5): 299-327.

8. Frost HM. The regional acceleratory phenomenon: a review. Henry Ford Hosp Med J 1983; 31(1): 3-9.

9. Sangsuwon C, Alansari S, Nervina J. Micro-osteoperforations in accelerated orthodontics. Clin Dent Rev 2018; 2(1): 4-11.

10. Usumi-Fujita R, Hosomichi J, Ono N, Shibutani N, Kaneko S, Shimizu Y, et al. Occlusal hypofunction causes periodontal atrophy and VEGF/VEGFR inhibition in tooth movement. Angle Orthod 2012; 83(1): 48-56.

11. Niida S, Kaku M, Amano H, Yoshida H, Kataoka H, Nishikawa $\mathrm{S}$, et al. Vascular endothelial growth factor can substitute for macrophage colony-stimulating factor in the support of osteoclastic bone resorption. J Exp Med 1999; 190(2): 293-98.

12. Nakagawa M, Kaneda T, Arakawa T, Morita S, Sato T, Yomada $\mathrm{T}$, et al. Vascular endothelial growth factor (VEGF) directly enhances osteoclastic bone resorption and survival of mature osteoclasts. FEBS letters 2000; 473(2): 161-64.

13. Street J, Bao M, deGuzman L, Bunting S, Peale FV, Ferrara N, et al. Vascular endothelial growth factor stimulates bone repair by promoting angiogenesis and bone turnover. Proc Natl Acad Sci 2002; 99(15): 9656-61.

14. Eui-seok SU, Hiroyuki W, Junichiro I, Kunimichi S. The effects of occlusal hypofunction and its recovery on the periodontal tissues of the rat molar: ED1 immunohistochemical study. Orthodontic waves: J Jap Orthod Soc 2002; 61(3): 165-72.

15. Kohno T, Matsumoto Y, Kanno Z, Warita H, Soma K. Experimental tooth movement under light orthodontic forces: rates of tooth movement and changes of the periodontium. J Orthod 2002; 29(2): 129-36.

16. Ren Y, Maltha JC, Van't Hof MA, Kuijpers-Jagtman AM. Age effect on orthodontic tooth movement in rats. J Dent Res 2003; 82(1): 38-42.

17. Alikhani M, Raptis M, Zoldan B, Sangsuwon C, Lee YB, Alyami B, et al. Effect of micro-osteoperforations on the rate of tooth movement. Am J Orthod Dentofacial Orthop 2013; 144(5): $639-48$.

18. Cramer CL, Campbell PM, Opperman LA, Tadlock LP, Buschang $\mathrm{PH}$. Effects of micro-osteoperforations on tooth movement and bone in the beagle maxilla. Am J Orthod Dentofacial Orthop 2019; 155(5): 681-92. 
19. Aboalnaga AA, Fayed MM, El-Ashmawi NA, Soliman SA. Effect of micro-osteoperforation on the rate of canine retraction: a split-mouth randomized controlled trial. Progorthod 2019; 20(1): 21-7.

20. Ibadullah $\mathrm{k}$, Shaheed S. Effect of miniscrews perforation on max- illary canine retraction rate. Pak Oral Dent J 2018; 38(3): 309-13. 21. Sivarajan S, Doss JG, Papageorgiou SN, Cobourne MT, Wey MC. Mini-implant supported canine retraction with micro-osteoperforation: A split-mouth exploratory randomized clinical trial. Angle Orthod 2019; 89(2): 183-89. 